\title{
Alcohol ingestion induces pancreatic islet dysfunction and apoptosis via mediation of FGF21 resistance
}

\author{
Bao Chen Yang, Shang Ying Wu, Po Sing Leung \\ School of Biomedical Sciences, Faculty of Medicine, The Chinese University of Hong Kong, Hong Kong, China \\ Contributions: (I) Conception and design: BC Yang, PS Leung; (II) Administrative support: PS Leung; (III) Provision of study materials or patients: PS \\ Leung; (IV) Collection and assembly of data: BC Yang, SY Wu; (V) Data analysis and interpretation: BC Yang, PS Leung; (VI) Manuscript writing: \\ All authors; (VII) Final approval of manuscript: All authors. \\ Correspondence to: Po Sing Leung, PhD. Room 609A, 6/F, Lo Kwee-Seong Integrated Biomedical Sciences Building, The Chinese University of Hong \\ Kong, Shatin, N.T., Hong Kong, China. Email: psleung@cuhk.edu.hk.
}

\begin{abstract}
Background: Disruption of $\beta$-cell insulin secretion and viability caused by excessive ethanol consumption increases type 2 diabetes mellitus (T2DM) pathogenesis risk. Fibroblast growth factor 21 (FGF21) plays a significant role in regulating lipid and glucose homeostasis. Recently, FGF21, best known for its role in lipid and glucose homeostasis regulation, and its obligate co-receptor $\beta$-klotho have been shown to inhibit ethanol ingestion and metabolism. It remains unclear whether heavy ethanol intake modulates islet FGF21 expression and function. This study investigated the relationship between ethanol exposure, FGF21, and islet function in vivo/ex vivo islet and in vitro cell models.
\end{abstract}

Methods: Mice were gavaged with $3.5 \mathrm{~g} / \mathrm{kg}$ ethanol or saline for 1-3 weeks (long-term exposure). Human MIN6 cells and isolated islets were cultured and treated with $80 \mathrm{mM}$ ethanol for $24 \mathrm{~h}$ (short-term exposure) to mimic excessive ethanol consumption. We applied the oral glucose tolerance test (OGTT), blood glucometry, enzyme-linked immunosorbent assay (ELISAs) for insulin and FGF21, glucose stimulated insulin secretion (GSIS) testing, reverse-transcription (RT)-polymerase chain reaction (PCR), and western blot experiments.

Results: Long-term ethanol treatment induced FGF21 resistance in mouse pancreatic islets. Moreover, ethanol exposure damaged insulin secretory ability and glucose homeostasis. In vitro and ex vivo experiments showed that short-term ethanol treatment upregulated the expression of FGF21 signaling pathway-related genes and proteins, without affecting $\beta$-cell survival or function.

Conclusions: Long-term ethanol consumption induces FGF21 resistance-mediated pancreatic $\beta$-cell dysfunction, and thus diabetes pathogenesis risk.

Keywords: $\beta$-klotho; diabetes; ethanol; fibroblast growth factor 21 (FGF21); pancreatic islet cells

Submitted Sep 26, 2019. Accepted for publication Jan 02, 2020.

doi: $10.21037 /$ atm.2020.02.129

View this article at: http://dx.doi.org/10.21037/atm.2020.02.129

\section{Introduction}

Alcohol addiction is a pervasive worldwide problem, causing 3.3 million deaths in 2010, and accounting for $5.9 \%$ of all deaths in the world (1). Drinking alcohol regularly increases the risk of adverse health outcome risks, including risks for fatty liver, neurological, cardiovascular, and metabolic diseases. Notably, heavy alcohol drinkers are at an elevated risk of developing type 2 diabetes mellitus (T2DM) relative to non-drinkers. With respect to T2DM pathogenesis, it has been suggested that alcohol use increases risk of islet dysfunction, whereby $\beta$-cell apoptosis and hypoproliferation underlying insulin resistance leads to poor glucose homeostasis (2-4). Human studies have shown that alcohol consumption-induced $\beta$-cell disruption is related to mitochondrial dysfunction, oxidative stress, and increased 
production of reactive oxygen species in pancreatic islets $(5,6)$.

Fibroblast growth factor 21 (FGF21) is an endocrine factor expressed in liver, adipose, and pancreas tissues. Chronic FGF21 administration has been reported to increase pancreatic islet numbers, increase insulin biosynthesis, and promote $\beta$-cell survival in $d b / d b$ mice $(7,8)$. Pharmacological FGF21 doses have been shown to increase glucose uptake, improve glucose clearance, and lower blood glucose and triglyceride levels in high-fat diet-induced obese mice and to reduce glucolipotoxicity in INS-1 cells. Moreover, FGF21 over-expressing transgenic mice exhibit a lower plasma glucagon level than similar mice not induced to over-express FGF21 (9-11).

Several recent studies have described indirect effects of FGF21 on acute ethanol metabolism. Marked increases in serum FGF21 levels triggered by acute and subchronic alcohol consumption in both humans and rodents have been shown to have hepato-protective effects, including suppression of inflammatory reactions, fibrosis, and lipid accumulation (12-15). In addition, FGF21 has been reported to alter gastric emptying rate and early ethanol metabolism, without affecting ethanol dehydrogenase activity or aldehyde dehydrogenase 2 activity (16). On the other hand, FGF21 deficiency can aggravate ethanolinduced liver injury. It has been suggested that FGF21 may regulate drinking behavior by reducing neural release of dopamine in target tissues, similar to the consumptionreducing effects of satiety-related gut peptides, while affecting sympathetic regulation of ethanol-induced adipose lipolysis (17-20).

Although mitochondrial dysfunction and oxidative stress can well explain ethanol-induced $\beta$-cell failure, we do not yet have a clear understanding of the relationships among drinking alcohol, islet function, and FGF21 signaling. In the present study, to investigate the impact of long-term ethanol consumption on glucose homeostasis in vivo, we applied the oral glucose tolerance test (OGTT), conducted glucometer blood glucose level testing, conducted an enzyme-linked immunosorbent assays (ELISAs) for insulin and FGF21, and performed glucose stimulated insulin secretion (GSIS) testing on islets from mice subjected to chronic ethanol administration via gavage. Reversetranscription (RT)-polymerase chain reaction (PCR) experiments were conducted to examine the effects of ethanol exposure on the expression of islet function-related genes. We hypothesized that chronic ethanol exposure would lead to FGF2 1 resistance and $\beta$-cell impairment, thereby increasing the risks of T2DM.

\section{Methods}

\section{Animal study}

Male 10-week-old C57/6J mice were supplied by the Laboratory Animal Service Center of the Chinese University of Hong Kong for this study. The experimental procedures were approved by the Animal Experimentation Ethics Committee of the Chinese University of Hong Kong. The mice were housed at $22 \pm 2{ }^{\circ} \mathrm{C}$ with a 12 -h light/ dark cycle and free access to food and water. The mice were divided into ethanol and saline control groups. Mice in the ethanol group were gavaged with a dose of $3.5 \mathrm{~g} / \mathrm{kg}$ bodyweight ethanol (30\%) daily in the morning for 1 week, 2 weeks, or 3 weeks. Mice in the saline control group were gavaged with an equivalent volume of saline for 1,2 , or 3 weeks.

\section{Islet isolation and culture}

Pancreatic islets were isolated from mice as previously described (21). Subsequently, the intact isolated pancreatic islets were cultured in $5.6 \mathrm{mM}$ glucosecontaining RPMI 1640 medium supplemented with $10 \%$ fetal bovine serum (FBS; Gibco Laboratories, Grand Island, NY), 100 units/mL penicillin, and $100 \mu \mathrm{g} / \mathrm{mL}$ streptomycin (Invitrogen).

\section{Human islet and cell treatments}

Human islets were purchased from Prodo Laboratories Inc. (Irvine, CA) and shipped in PIM(T) medium within $7 \mathrm{~d}$ of being isolated. Upon arrival, the islets were left undisturbed overnight in recovery medium at $37{ }^{\circ} \mathrm{C}$. The islets were placed in human $A B$ serum supplemented with $10 \mathrm{mM}$ HEPES, $1 \mathrm{mM}$ sodium pyruvate, $100 \mathrm{U} / \mathrm{mL}$ penicillin/ streptomycin, and 10\% FBS for 2-4 days before treatment. MIN6 cells were purchased from AddexBio and cultured in DMEM containing $25 \mathrm{mM}$ glucose, $2 \mathrm{mM}$ L-glutamine, and $1 \mathrm{mM}$ sodium pyruvate supplemented with $15 \% \mathrm{FBS}$ (Thermo Fisher Scientific, USA), $100 \mathrm{U} / \mathrm{mL}$ streptomycin, $100 \mathrm{U} / \mathrm{mL}$ penicillin (Invitrogen, USA), and $75 \mu \mathrm{M}$ $\beta$-mecaptoethanol (Sigma, USA) in an incubator set to $37^{\circ} \mathrm{C}$ with $5 \% \mathrm{CO}_{2}$.

Ethanol was diluted with growth medium to a final concentration $80 \mathrm{mM}$ (based on legal driving limits in the USA, UK, and other countries). MIN6 cells and human islets were exposed to this ethanol solution or only vehicle (growth medium without ethanol) for $24 \mathrm{~h}$. 
Table 1 Real-time PCR primer sequences

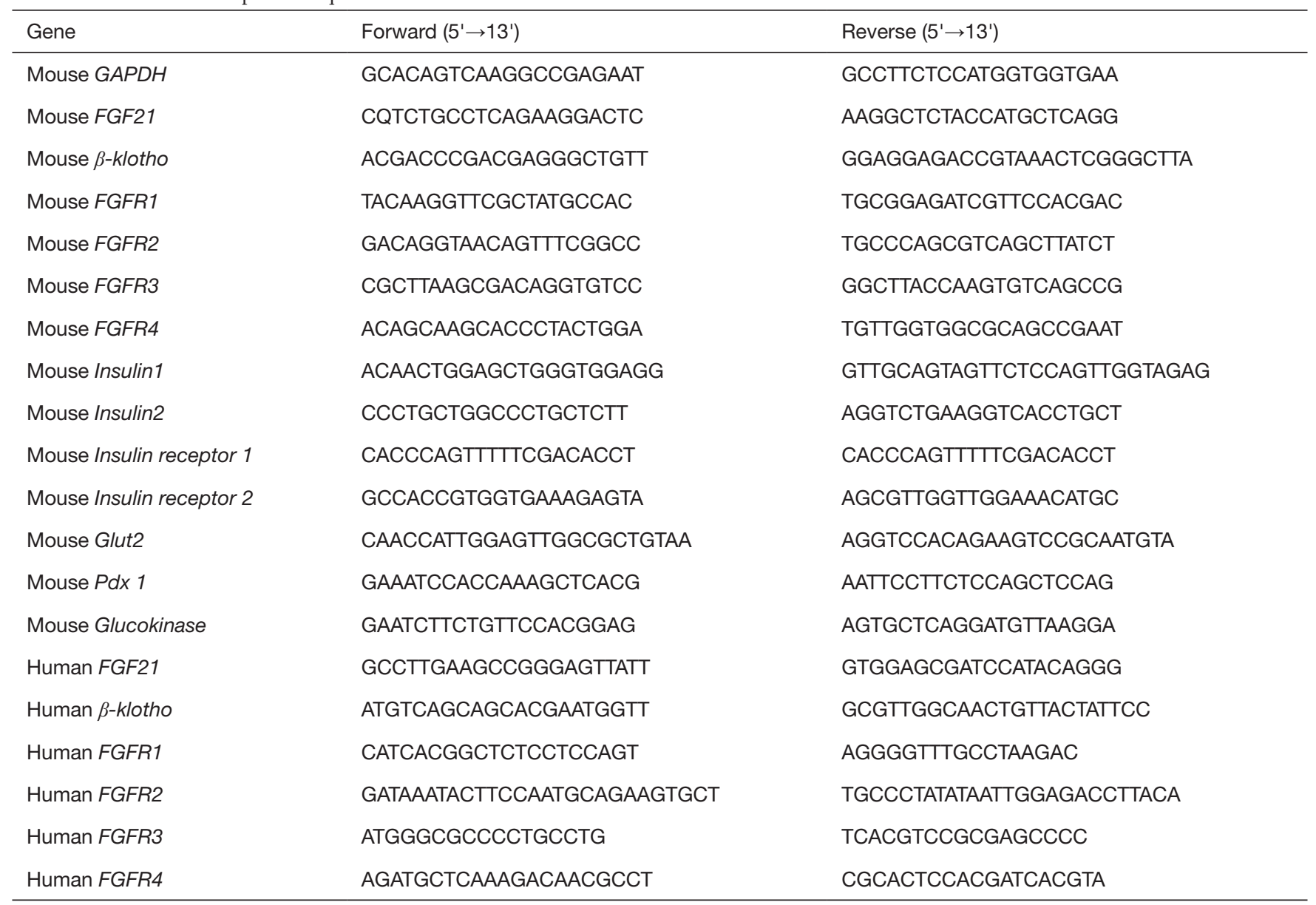

\section{RT-PCR analysis}

Total RNA was extracted from islets and from MIN 6 cells with TRIzol reagent (Invitrogen) according to the manufacturer's instructions. RT of first-strand cDNA was performed with a PrimeScript reverse transcriptase master mix kit (Takara Bio Inc., Kusatsu, Japan). Gene expression was measured by conventional or real-time PCR, wherein cDNA samples were mixed with SYBR green QPCR master mix (Applied Biosystems, Walttham, MA) and specific primers (Table 1). The fold change in mRNA expression relative to the control group was determined with the $2^{-\Delta \Delta C t}$ method and normalized to gluceraldehude-3-hosphate dehydrogenase (GAPDH) mRNA levels.

\section{Western blot analysis}

Islet and cell proteins were extracted with RIPA. Extracted proteins were separated by $8-12 \%$ sodium dodecyl sulfate- polyacrylamide gel electrophoresis, and transferred to nitrocellulose membranes (Bio-rad Heidemannstraße, Germany), which were blocked with $5 \%$ milk and then proved overnight with anti-FGF21 (Abcam, Cambridge, UK), anti-phospho-FRS, 2-anti-FRS2, anti-phosphoERK1/2, anti-ERK1/2 (Cell Signaling Technology, Boston, MA), or anti- $\beta$-actin (Santa Cruz Biotechnology, Santa Cruz, CA) primary antibodies at room temperature (RT). Horseradish peroxide-conjugated secondary antibodies were incubated at RT with membranes for $2 \mathrm{~h}$ after washing with phosphate buffered saline with $0.1 \%$ Tween-20. Labeled protein bands were visualized on autoradiography films (Fuji Film, Tokyo, Japan) following application of ECL detection reagent (GE healthcare, Chicago, IL). Protein bands were quantitated in Image software (National Institutes of Health, Bethesda, MD) and normalized to $\beta$-actin. The primary and secondary antibodies used are listed in Table 2. 
Table 2 Antibodies used in Western blotting and immunohistochemistry

\begin{tabular}{lccc}
\hline Antibody & Dilution & Host Species & Supplier \\
\hline FGF21 & $1: 1,000$ & Rabbit & Abcam \\
p-ERK & $1: 1,000$ & Rabbit & Cell Signaling \\
ERK & $1: 1,000$ & Rabbit & Cell Signaling \\
p-FRS2 & $1: 1,000$ & Rabbit & Cell Signaling \\
FRS2 & $1: 1,000$ & Rabbit & Cell Signaling \\
$\beta$-actin & $1: 1,000$ & Mouse & Santa Cruz \\
HRP-anti-rabbit IgG & $1: 1,000$ & Donkey & Amersham \\
HRP-anti-mouse IgG & $1: 1,000$ & Sheep & GE Healthcare \\
\hline
\end{tabular}

Table 3 Antibodies used in immunofluorescent labeling

\begin{tabular}{lccc}
\hline Antibody & Dilution & Host species & Supplier \\
\hline FGF21 & $1: 200$ & Rabbit & Abcam \\
Insulin & $1: 200$ & Guinea pig & Life Technologies \\
\hline
\end{tabular}

\section{Immunocytochemistry and immunofluorescent examinations}

Fresh mouse pancreas was embedded in O.C.T. compound (Tissue Tek, Sakura, Japan) and frozen in nitrogen immediately. Cryostat sections were sliced at $6 \mu \mathrm{m}$ and fixed in 4\% paraformaldehyde (Sigma-Aldrich) at RT for $15 \mathrm{~min}$. After being rinsed with phosphate buffered saline (PBS) three times, the sections were blocked with $2 \%$ bovine serum albumin (Sigma-Aldrich) for $1 \mathrm{~h}$ and incubated with primary antibodies at $4{ }^{\circ} \mathrm{C}$ for $12 \mathrm{~h}$. Sections were then incubated for $2 \mathrm{~h}$ with secondary antibodies conjugated with Alexa Fluor 568 (1:200; Life Technologies) and Alexa Fluor 488 (1:200; Life Technologies) for $2 \mathrm{~h}$ at RT. After counterstaining with 4',6'-diamidino-2-phenylindole (DAPI, 1:40,000, Life Technologies) and rinsing, samples were mounted and examined. Digital images were acquired on an Olympus FV1200 SIM Confocal System and analyzed with FLUOVIEW software. The primary and secondary antibodies used are listed in Table 3.

\section{In vivo glucose homoeostasis}

In preparation for the OGTT, mice were fasted for $6 \mathrm{~h}$, then gavaged with $2 \mathrm{~g} / \mathrm{kg}$ glucose. Blood glucose level was measured in blood drawn from the tail vein with a glucometer (Bayer Corporation, Robinson Township,
PA) immediately, 15, 30, 60, and 120 min after glucose administration. At the same time, serum insulin levels were measured with a mouse insulin ELISA kit (Antibody and Immunoassay Services, University of Hong Kong).

\section{GSIS}

Isolated islets were allowed to equilibrate in Krebs-Ringer bicarbonate buffer (KRBB, supplemented with $0.1 \%$ NEFAfree BSA and $10 \mathrm{mM}$ HEPES) with $1.7 \mathrm{mM}$ glucose for $1 \mathrm{~h}$. The islets or cells were then incubated in KRBB containing $1.7 \mathrm{mM}$ glucose for $1 \mathrm{~h}$, and in KRBB with $16.7 \mathrm{mM}$ glucose for an additional $1 \mathrm{~h}$. KRBB solution samples were subjected to insulin quantification with an ELISA kit (University of Hong Kong, China)

\section{Plasma FGF21 concentration}

Immediately upon collection, tail vein blood samples were placed on ice and then separated by centrifugation for $15 \mathrm{~min}$ at 3,000 rpm. Plasma FGF21 concentrations were measured with an FGF21-specific mouse ELISA kit (Antibody and Immunoassay Services, University of Hong Kong).

\section{Cell viability assay}

Metabolic activity of MIN6 cells was measured with a 3-(4,5-dimethyl-2-thiazolyl)-2,5-diphenyltetrazolium (MTT) bromide assay immediately after a 24-h ethanol treatment. The cells were seeded in a 96-well cell culture plate at $4 \times 10^{4}$ cells/well for 1 day, then incubated in $2 \%$ FBS media with or without ethanol for $24 \mathrm{~h}$. Subsequently, $0.15 \mathrm{mg}$ MTT was added to each well. After the medium was discarded, the cells were allowed to incubate for $3 \mathrm{~h}$ at $37^{\circ} \mathrm{C}$ and then $100 \mu \mathrm{L}$ dimethyl sulfoxide was added to each well and the cells were left for $15 \mathrm{~min}$ at RT. Finally, optical density at $490 \mathrm{~nm}$ was read in a microplate reader (SpectraMax i3x Multi-Mode Detection Platform, Molecular Devices, CA). Cell viability was expressed as a percentage of the quantity of cells observed in the nonethanol medium control group.

\section{Cell death rate}

MIN 6 cells were seeded at a density of $4 \times 10^{4}$ cells/well in a 96-well cell culture plate and cultured under experimentally indicated conditions. Cell death rate was determined by a cell death detection ELISA plus kit (Roche Applied Science) 
according to the manufacturer's instructions.

\section{Statistical analysis}

Results are displayed as means \pm standard errors (SEs). Groups were compared with two-tailed Student's t test or one-way analyses of variance (ANOVA) followed by Tukey's post hoc test or with a two-way ANOVA. In all cases, $\mathrm{P}<0.05$ was considered statistically significant.

\section{Results}

\section{Chronic ethanol consumption impairs glucose metabolism and insulin secretion ability}

Young adult mice did not show significant changes in blood glucose or insulin content relative to (equivalent-volume) saline controls after 1 week of being gavaged with ethanol (Figure 1A), but did show a reduced insulin peak after 2 weeks of ethanol gavage (Figure $1 B$ ) and reduced levels of insulin overall together with reduced glucose tolerance, as evidenced by OGTT results, after 3 weeks of ethanol gavage (Figure 1C). Meanwhile, GSIS testing showed that insulin secretory ability, which was similar between the ethanol and saline control groups after one-week ethanol gavage, became impaired in the ethanol group, relative to the saline control group, after 2 weeks and this impairment became more pronounced after 3 weeks (Figure 1D).

\section{Chronic ethanol consumption induces FGF21 resistance}

A progressive reduction in mRNA levels of the FGF21 receptor co-factor $\beta$-klotho and FGF receptors was seen with increasing ethanol gavage time (Figure $2 A, B$ ). The mRNA levels of $\beta$-klotho and FGF receptor genes were reduced in the ethanol group, relative to the control group, at the 2-and 3-week treatment time points. Meanwhile, serum FGF21 levels were shown to increase slightly in the first and second weeks of ethanol administration, reaching approximately double control levels by the 3 -week time point (Figure 2C). Correspondingly, FGF21 protein levels were upregulated in isolated islets from mice in the ethanol group (Figure 2D). Similar results were also found as demonstrated by immunostaining data (Figure S1).

\section{Long-term ethanol drinking reduces expression of islet function related genes}

Compared to saline control group levels, mRNA expression of the insulin encoding genes Insulin1 (Ins1) and Insulin2 (Ins2) began to decrease after 1 and 2 weeks, respectively, of ethanol administration, whereas mRNA expression of the insulin receptor substrate genes Insulin receptor1 Insulin receptor 1 (Irs1) and Insulin receptor 2 (Irs2) showed an apparent upregulation at the 1-week time point, followed by a steady decrease through weeks 2 and 3 (Figure $3 A$ ). The expression patterns over the analyzed time points of the islet function related genes [pancreatic and duodenal homeobox $1(P d x-1)]$ and glucose transporter $2($ Glut2) were similar to those of Ins1 and Ins2, whereas that of glucokinase (Glk) was similar the patterns observed for Irs1 and Irs2 (Figure 3B).

\section{Ethanol exposure for $24 \mathrm{~b}$ alters buman $\beta$-cell function}

As shown in Figure 4A, human islet and MIN6 cells were subjected to 24-h ethanol exposure exhibited a robust insulin secretory response to glucose treatments in an in vitro GSIS experiment. The 24-h ethanol exposure treatment did not significantly affect cell death rate (Figure $4 B$ ) or cell viability (Figure $4 C$ ). After the 24-h ethanol treatment, however, we observed obvious increases in the mRNA expression of $F G F 21$, the FGF receptor genes FGFR1 and FGFR3, and the FGF receptor cofactor $\beta$-klotho, which showed the most pronounced increase (Figure $5 A$ ). Notably, in a parallel experiment with isolated human pancreatic islets, 24-h ethanol exposure resulted in significantly increased mRNA expression of $F G F 21$, all four FGF receptor genes (FGFR1, FGFR2, FGFR3, and FGFR4), and the FGF receptor cofactor $\beta$-klotho (Figure $5 B$ ). Western blot protein analysis of these MIN6 cell groups showed significantly increased levels of phosphorylated FRS2 (fibroblast growth factor receptor substrate 2; an FGF21 signaling reporter) and phosphorylated ERK (extracellular-signal-regulated kinase) compared to the vehicle control group (Figure 5C).

\section{Discussion}

Although exogenous FGF21 has well-known pharmaceutical effects, including weight loss, increased insulin sensitivity, and improved blood glucose clearance $(22,23)$, and clinical studies have correlated alcohol consumption with insulin resistance and glucose intolerance $(5,24,25)$, little is known about FGF21 involvement in alcoholism effects on pancreatic islets and T2DM pathogenesis. In the current study, we report, for the first time, that ethanol exposure impairment of pancreatic islet glucose metabolism and insulin secretion ability is associated with FGF21 resistance. 
A

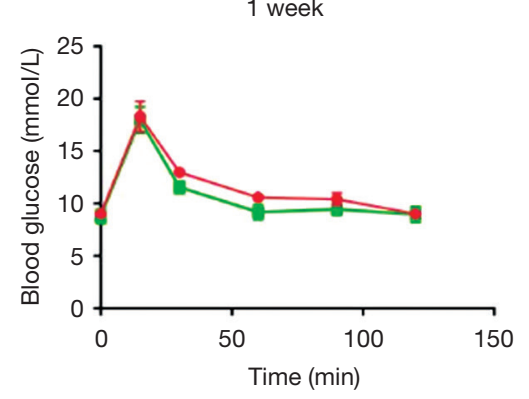

B

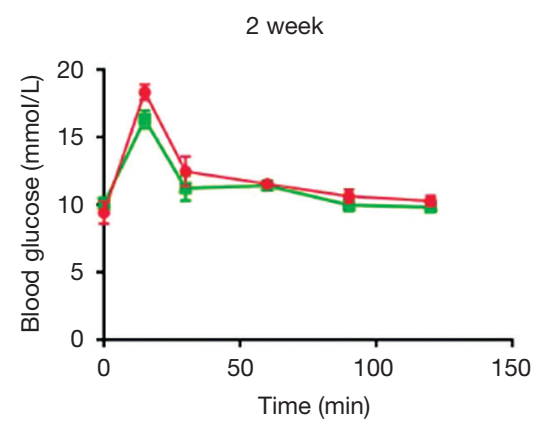

C

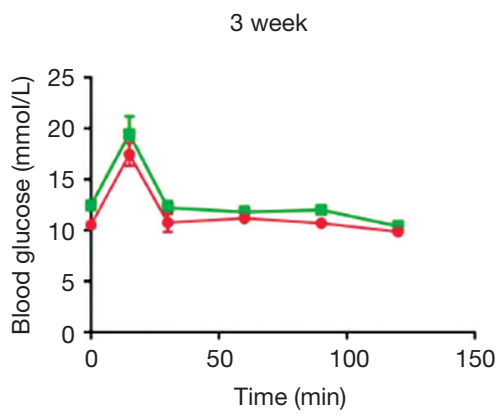

D
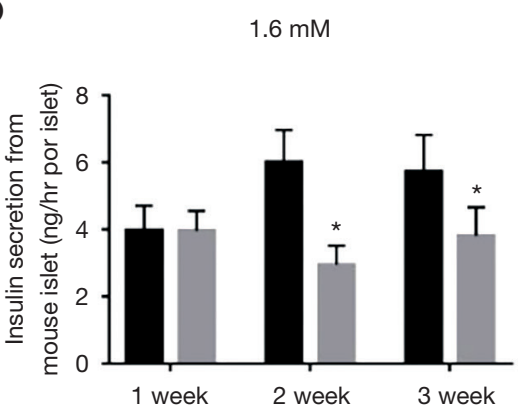

- Vehicle

- Ethanol

- Vehicle

- Ethanol

- Vehicle

- Ethanol

Vehicle

Ethanol
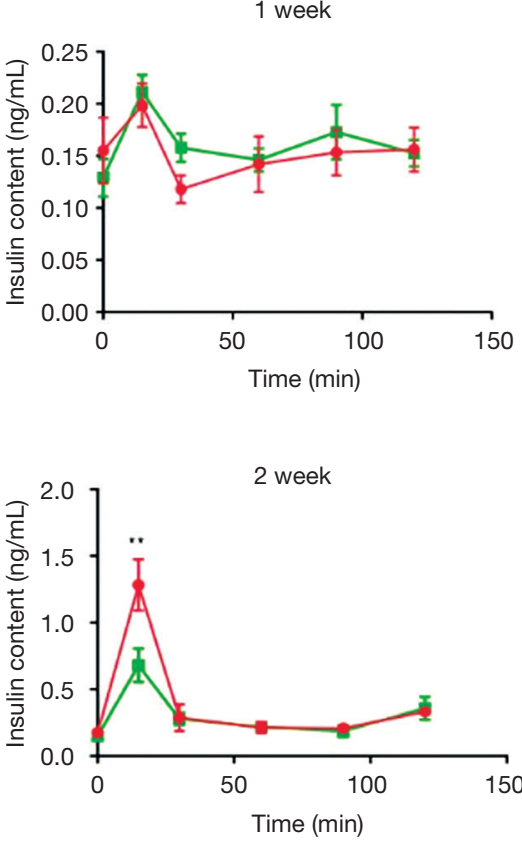

- Vehicle

$$
\text { - Ethanol }
$$

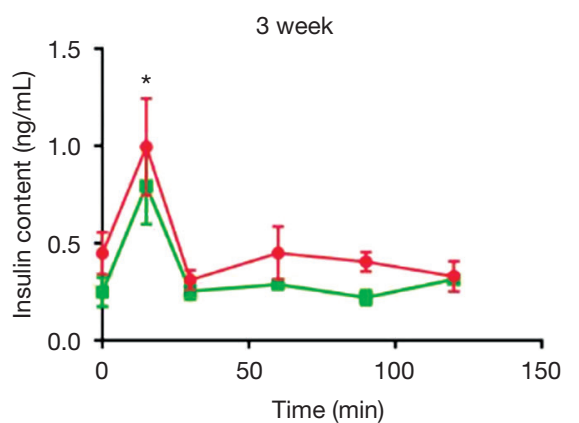

$\sim$ Vehicle

- Ethanol

$16.7 \mathrm{mM}$

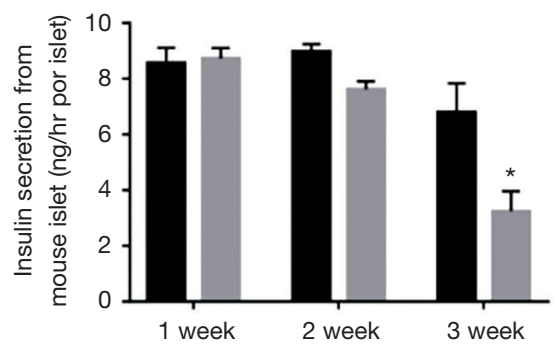

Vehicle

Ethanol

Figure 1 Chronic ethanol exposure impaired glucose metabolism. Over a period of weeks, daily gavaged ethanol led to reduced plasma insulin levels, which were not yet demonstrable after 1 week (A), but that continued to decrease and become significant through week 2 (B) and week 3 (C). GSIS tests were performed on islets isolated from the gavaged mouse groups at low (1.6 $\mathrm{mM})$ and high (16.7 $\mathrm{mM})$ glucose concentrations. (D) Graphic summary of ethanol treatment effects on insulin secretion by time point. Data are means $\pm \mathrm{SEs}$; ${ }^{*} \mathrm{P}<0.05$, ${ }^{* *} \mathrm{P}<0.01$ vs. matched vehicle group ( $\mathrm{N}=5$ per treatment-time group). 

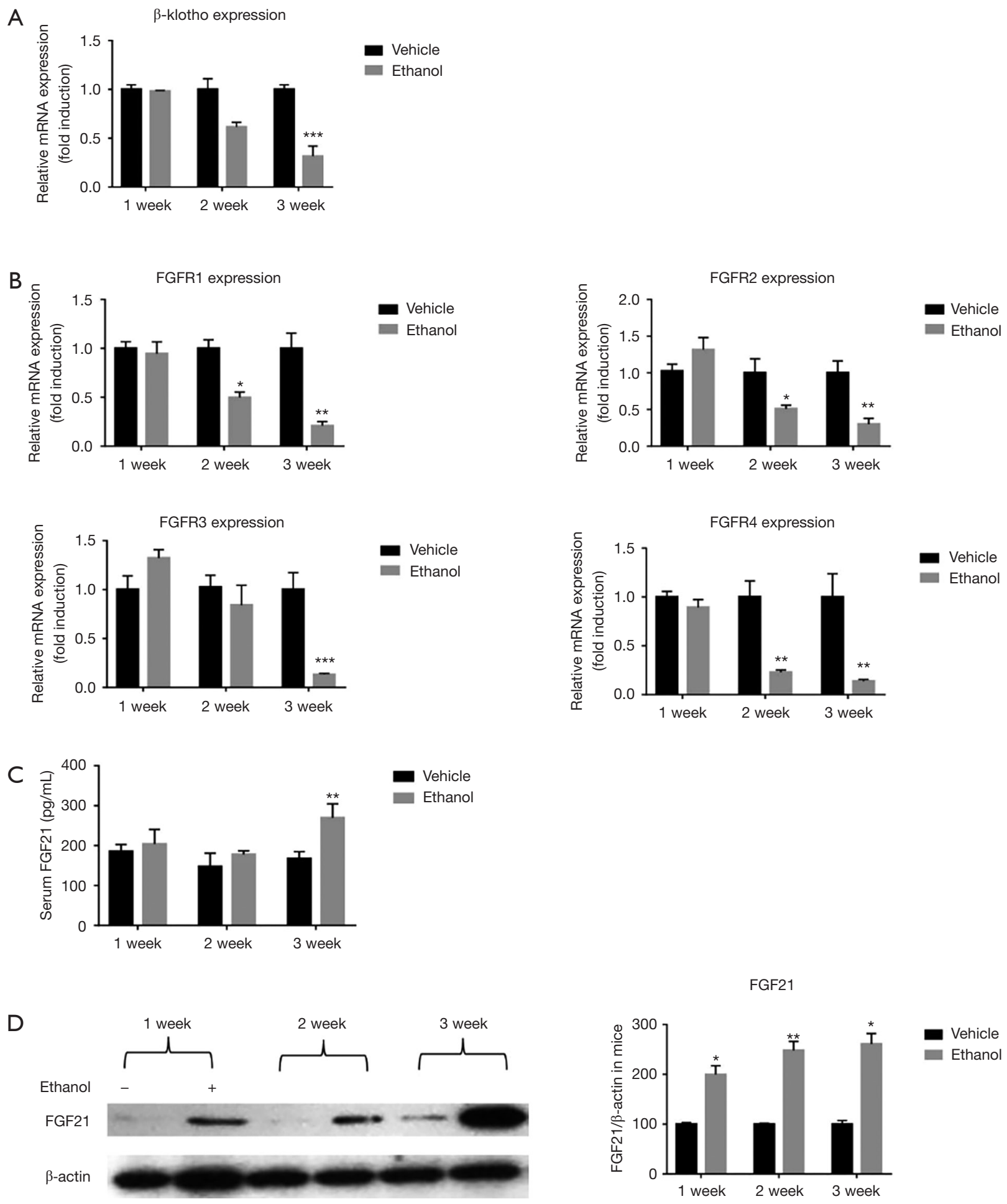

Figure 2 Chronic ethanol exposure induced FGF21 resistance. Quantitative RT-PCR determined relative $\beta$-klotho (A) and FGF receptor (FGFR) (B) mRNA levels in islets isolated from mice after 1-3 weeks of being gavaged with or without ethanol. (C) Increased levels of serum FGF21 levels in terminal bleed blood, determined by ELISAs, after 3 weeks of ethanol exposure. (D) Western blot, with $\beta$-actin densitometry loading control, demonstrating ethanol exposure-induced elevation of FGF21. Data are means $\pm \mathrm{SEs}$; ${ }^{*} \mathrm{P}<0.05$, ${ }^{* *} \mathrm{P}<0.01$, ${ }^{* * *} \mathrm{P}<0.001 v s$. time-matched saline gavaged group $(\mathrm{N}=5$ per treatment-time group). 
A
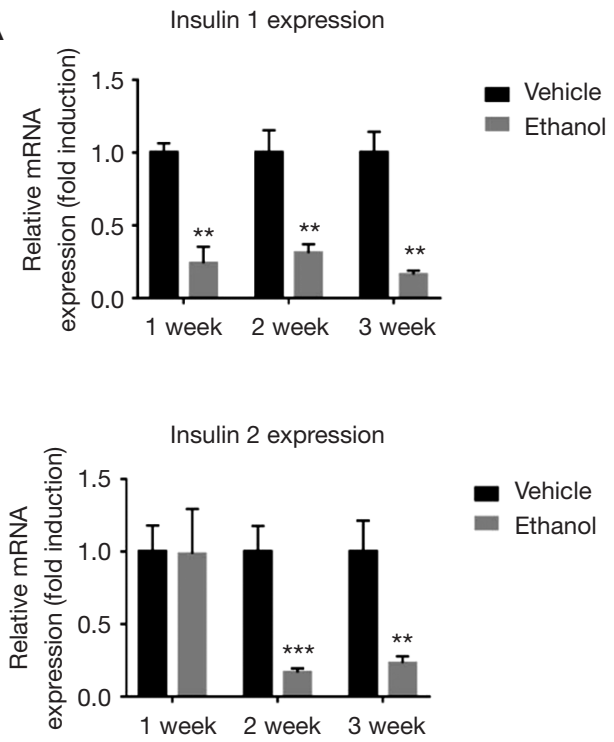
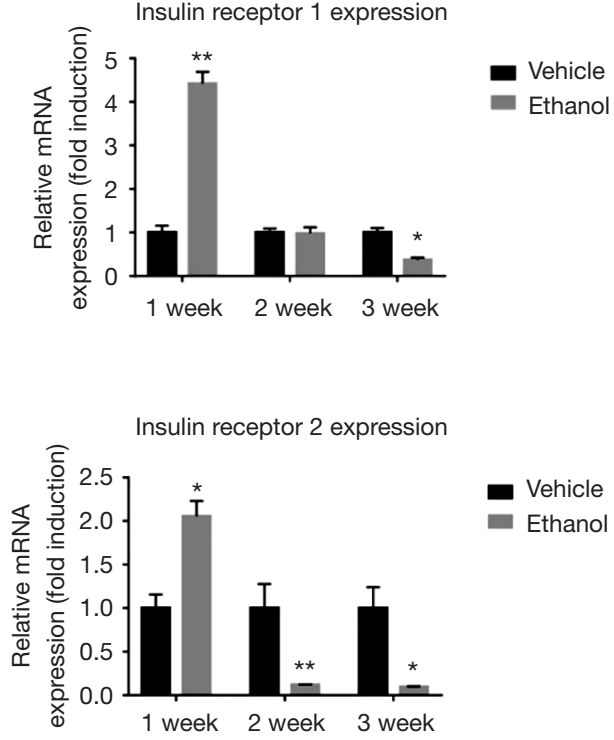
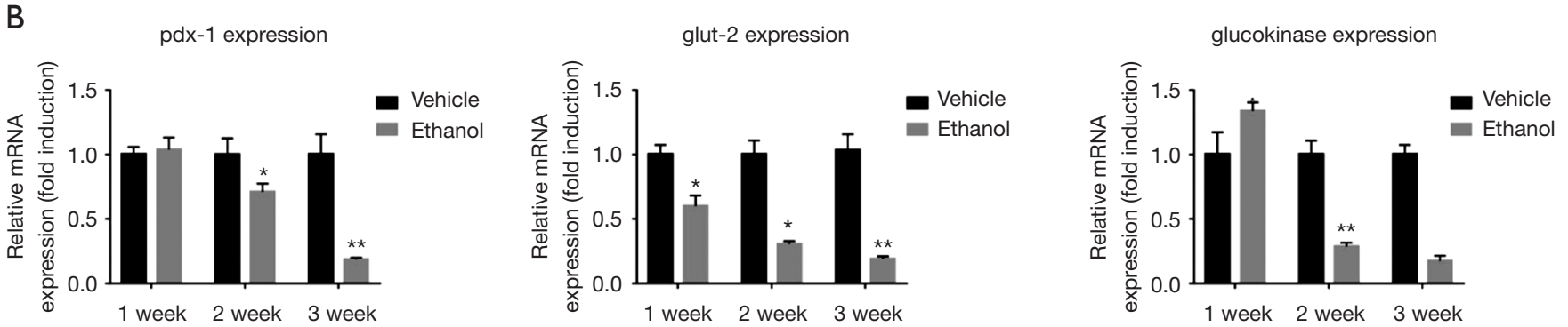

Figure 3 Long-term ethanol exposure reduced transcription levels of islet function-related genes. The mRNA expression of Ins1, Ins 2 and Insulin receptors (A) and function related genes $p d x-1, g l u t 2, g l k(B)$ in isolated islets were analyzed after 1, 2, or 3 weeks of daily alcohol (or saline vehicle) gavage. Data are means $\pm \mathrm{SEs} ;{ }^{*} \mathrm{P}<0.05$ and ${ }^{* *} \mathrm{P}<0.01$ vs. saline gavage group with same administration time $(\mathrm{N}=3$ per treatment-time group).

A GSIS

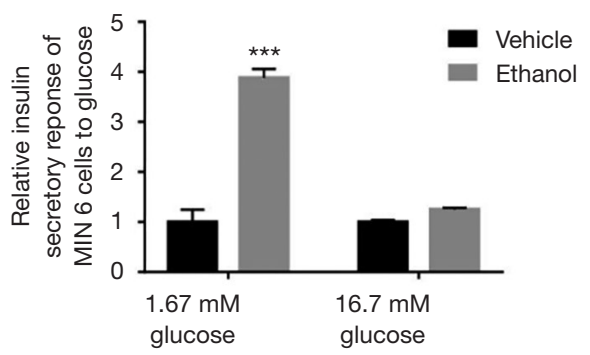

B

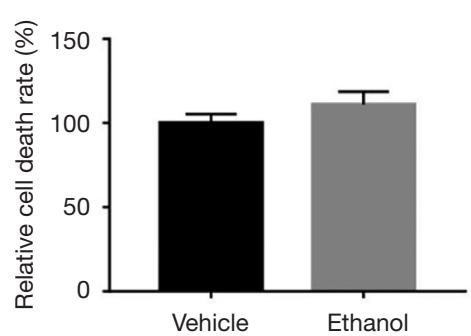

C

MIN 6 cells

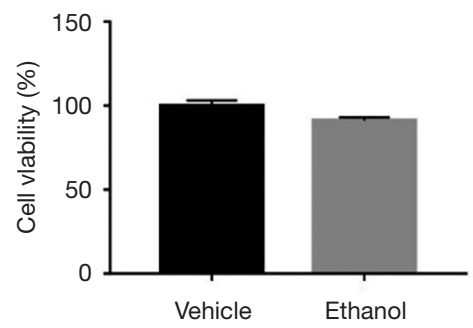

Figure 4 Short-term ethanol exposure did not impair pancreatic islet function and survival. GSIS, relative cell death rate, and cell viability (as determined by an MTT assay) were determined after 24-h exposure to ethanol or vehicle (control group). (A) Relative to MIN6 cells exposed to only vehicle, MIN6 cells exposed to ethanol showed an elevated response to $1.67 \mathrm{mM}$ glucose and a response to $16.7 \mathrm{mM}$ glucose similar to that seen in the control group. (B) Cell death rate and (C) cell viability were similar between the ethanol-exposed and vehicle control MIN6 cell groups. Data are means \pm SEs; $\mathrm{N}=6$ per group; ${ }^{*} \mathrm{P}<0.05$ and ${ }^{* * *} \mathrm{P}<0.001$ vs. vehicle group. 


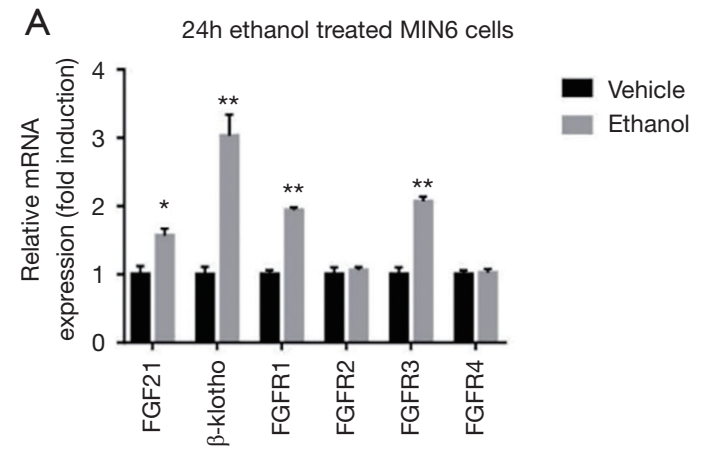

B 24h ethanol treated human islet
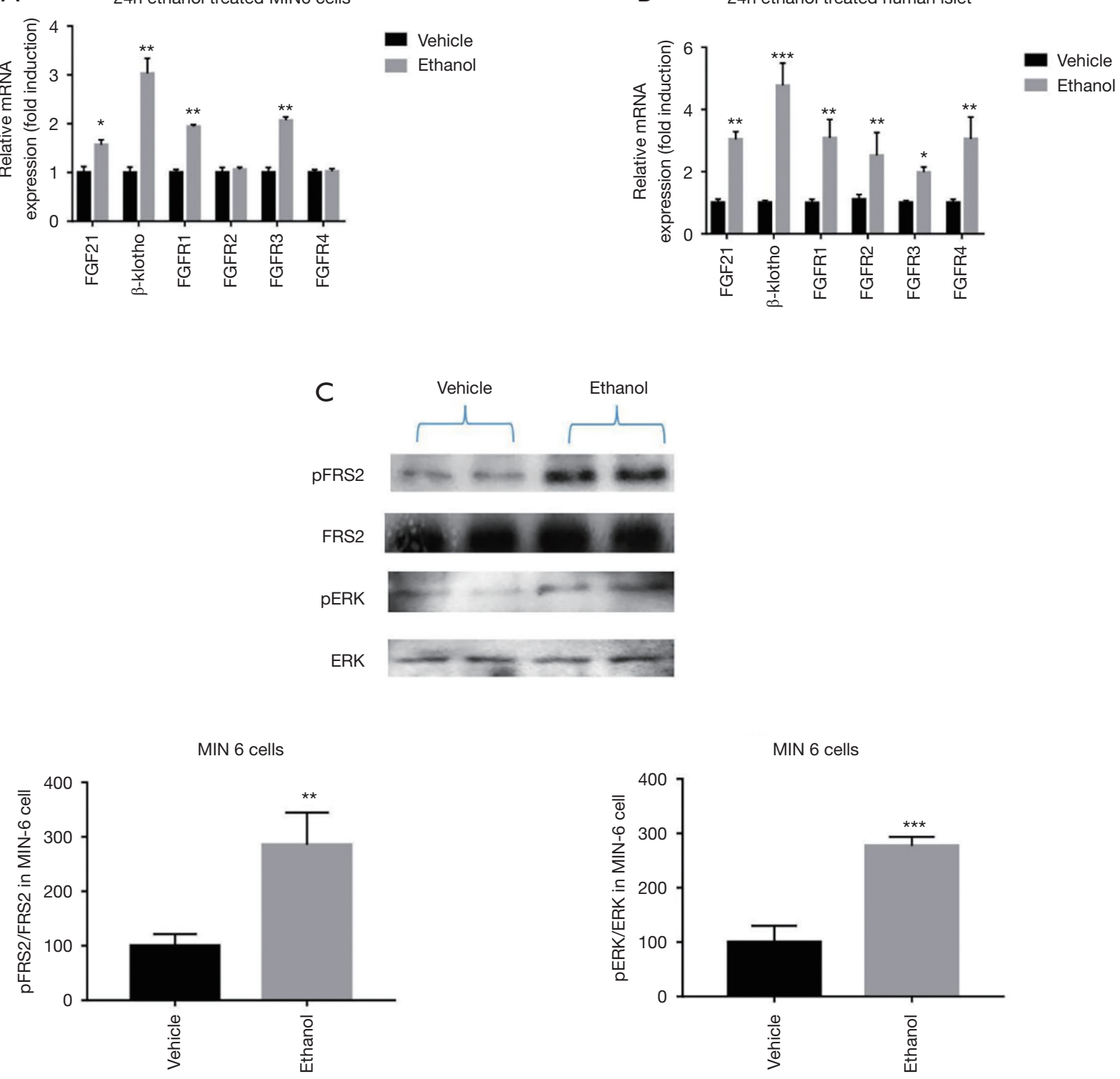

Figure 5 Alcohol exposure altered the expression of FGF21 pathway-related molecules in human islets and MIN6 cells. After 24-h exposure to ethanol (or vehicle), MIN6 cells or human islets were subjected to RT-PCR analysis of FGF21, KLB (encodes $\beta$-klotho), and FGFR1-4 mRNAs as well as Western blot protein analysis of unphosphorylated and phosphorylated (p) forms of FRS2 and ERK. (A,B) Standard quantitative RT-PCR showed that the ethanol group had elevated FGF21, KRB, FGFR1, and FGFR3 mRNA levels, compared to the vehicle control group. (C) Densitometric western blot analysis showed very significantly elevated levels of activated FRS2 (pFRS2/FRS2 ratio) and of activated ERK (pERK/ERK ratio) in the ethanol group compared to vehicle control cells. Data are means \pm SEs of 3-6 separate experiments; ${ }^{*} \mathrm{P}<0.05,{ }^{* *} \mathrm{P}<0.01$, and ${ }^{* * *} \mathrm{P}<0.001$ vs. vehicle group.

The development of FGF21 resistance in pancreatic islets may interfere with FGF21's ability to act a potent endocrine regulator of glucose and lipid metabolism and thus increase T2DM pathogenesis risk.
Our OGTT and GSIS results showed that long-term ethanol exposure reduced insulin levels and insulin secretary ability, consistent with prior studies reporting that chronic ethanol exposure can reduce insulin secretion, increase $\beta$-cell 
apoptosis and decrease $\beta$ cell mass (26,27). Islets isolated from mice subjected to long-term ethanol exposure showed marked reductions in Ins1, Ins 2, Irs1, and Irs 2 mRNA levels at the 2- and 3-week exposure time points. Chronic ethanol exposure also led to reductions in the mRNA expression of the islet function related genes $P d x-1, G l u t 2$, and Glk within the 3-week experimental period $(28,29)$. These data support the notion that chronic ethanol consumption induces pancreatic $\beta$-cell dysfunction and apoptosis (30).

Because previous studies showing that subchronic and acute ethanol drinking can cause substantial increases in serum FGF21 levels in both humans and mice $(31,32)$, we postulated that FGF21 resistance development may be a mediator of ethanol-induced pancreatic islet dysfunction. We confirmed in this study that long-term alcohol consumption (3 weeks) did indeed result in increased serum FGF21 levels in mice in vivo. Moreover, in isolated human islets, 24-h ethanol exposure increased FGF21, FGFR1-4, and $\beta$-klotho mRNA levels. Given that FGF2 1 resistance is characterized by increased levels of circulating FGF21 levels concomitant with decreased FGF21 receptor expression (33-35), these findings suggest that our ethanol treatments produced a state of FGF21 resistance. Meanwhile, our GSIS, cell death rate, and cell viability data showing that short-term ethanol exposure did not impair $\beta$-cell function or survival support the hypothesis that FGF21 may protect pancreatic islets from ethanol-induced pancreatic islet damage similar to the way that it has been shown to be protective against ethanol-induced hepatic damage and the progression of alcoholic liver disease in an acute alcohol drinking model (36-38).

The results of our analysis of ethanol exposure effects on FGF21 signaling pathway component expression support the notion that FGF21 resistance has a strong relationship with pancreatic islet dysfunction (39-41). Islets from mice exposed to our long-term binge drinking model had upregulated levels of phosphorylated FRS2 and phosphorylated ERK, which mediate essential steps in FGF21 signaling (42), leading to downstream changes in gene expression $(43,44)$, in addition to increased mRNA expression of FGF21, $\beta$-klotho, and FGF receptors.

Duration is an important factor in alcoholism-associated pancreatic disease $(45,46)$. Thus, we investigated the effects of ethanol exposure on pancreatic islets over multiple time points. After 1 week of ethanol administration (short-term exposure), GSIS and OGTT results remained quite similar between the ethanol exposed and control groups and the expression of FGF21, FGF receptors, and the FGF receptor co-factor $\beta$-klotho were only slightly or negligibly raised in the ethanol exposed group. However, substantial changes in these variables were readily apparent after 2 weeks of ethanol administration, and these changes showed further progression by the 3 -week time point. Thus, our data indicate that islet function is unlikely to be disrupted by short-term ethanol consumption, at least in the range of the ethanol concentrations used here $(47,48)$. Notwithstanding, an apparent pre-FGF21 resistance islet state induced by short-term ethanol exposure suggests that with additional exposure time, complete FGF21 resistance and consequent pancreatic islet dysfunction will develop if the ethanol exposure becomes a long-term influence.

\section{Conclusions}

In summary, the present study demonstrates a new link between pancreatic islet ethanol metabolism and FGF21 resistance, complementing prior work reporting that diabetic hyperglycemia leads to FGF21 resistance in pancreatic islets (49). Our findings suggest that short-term ethanol exposure may induce a pre-FGF21 resistance state, which, although not islet impairing itself, evolves into clinically significant islet FGF21 resistance and functional impairment if there is continued ethanol exposure. These results support the notion that the development of FGF21 resistance in response to chronic alcohol consumption could have an increased risk of developing T2DM. In this sense, FGF21 levels are proposed to serve as a measurement for the pancreatic cell function. We cannot, however, exclude the possibility for the effects of ethanol consumption on the dedifferentiation and apoptosis of pancreatic cells. In fact, dedifferentiation and apoptosis are very important factors for the determination of pancreatic cells dysfunction. Future work should be focused on the detailed mechanism(s) whereby the dedifferentiation and apoptosis of pancreatic alcoholism might be involved.

\section{Acknowledgments}

Funding: The work described in this paper was supported by the General Research Grants Council of the Hong Kong Special Administrative Region, China (Ref. \#CUHK14107415), awarded to PS Leung.

\section{Footnote}

Conflicts of Interest: The authors have no conflicts of interest to declare. 
Ethical Statement: All authors are accountable for all aspects of the work, including full data access, integrity of the data and the accuracy of the data analysis. All the experimental procedures were approved by the relevant institutional committee on the use of animals of The Chinese University of Hong Kong.

Open Access Statement: This is an Open Access article distributed in accordance with the Creative Commons Attribution-NonCommercial-NoDerivs 4.0 International License (CC BY-NC-ND 4.0), which permits the noncommercial replication and distribution of the article with the strict proviso that no changes or edits are made and the original work is properly cited (including links to both the formal publication through the relevant DOI and the license). See: https://creativecommons.org/licenses/by-nc-nd/4.0/.

\section{References}

1. Hingson RW, Heeren T, Zakocs RC, et al. Magnitude of alcohol-related mortality and morbidity among US college students ages 18-24. J Stud Alcohol 2002;63:136-44.

2. Vonlaufen A, Wilson JS, Apte MV. Molecular mechanisms of pancreatitis: current opinion. J Gastroenterol Hepatol 2008;23:1339-48.

3. Howard AA, Arnsten JH, Gourevitch, MN. Effect of alcohol consumption on diabetes mellitus. Ann Intern Med 2004;140:211.

4. Holst C, Becker U, Jørgensen ME, et al. Alcohol drinking patterns and risk of diabetes: a cohort study of 70,551 men and women from the general Danish population. Diabetologia 2017;60:1941-50.

5. Cullmann M, Hilding A, Östenson CG. Alcohol consumption and risk of pre-diabetes and type 2 diabetes development in a Swedish population. Diabet Med 2012;29:441-52.

6. Ajani UA, Hennekens CH, Spelsberg A, et al. Alcohol consumption and risk of type 2 diabetes mellitus among US male physicians. Arch Intern Med 2000;160:1025-30.

7. Coate KC, Hernandez G, Thorne CA, el at. FGF21 is an exocrine pancreas secretagogue. Cell Metab 2017;25:472-80.

8. Xie T, Leung PS. Fibroblast growth factor 21: a regulator of metabolic disease and health span. Am J Physiol Endocrinol Metab 2017;313:E292-302.

9. Kharitonenkov A, Shiyanova TL, Koester A, et al. FGF-21 as a novel metabolic regulator. J Clin Invest 2005;115:1627-35.

10. Kharitonenkov A, Shanafelt AB. FGF21: a novel prospect for the treatment of metabolic diseases. Curr Opin Investig
Drugs 2009;10:359-64.

11. Kharitonenkov A, Larsen P. FGF21 reloaded: challenges of a rapidly growing field. Trends Endocrinol Metab 2011;22:81-6.

12. Chen S, Zhao X, Wan J, et al. Dihydromyricetin improves glucose and lipid metabolism and exerts anti-inflammatory effects in nonalcoholic fatty liver disease: A randomized controlled trial. Pharmacol Res 2015;99:74-81.

13. Talukdar S, Owen BM, Song P, et al. FGF21 regulates sweet and alcohol preference. Cell Metab 2016;23:344-9.

14. Fisher FM, Chui PC, Nasser IA, et al. Fibroblast growth factor 21 limits lipotoxicity by promoting hepatic fatty acid activation in mice on methionine and choline-deficient diets. Gastroenterology 2014;147:1073-83.e6.

15. Afshar M, Richards S, Mann D, et al. Acute immunomodulatory effects of binge alcohol ingestion. Alcohol 2015;49:57-64.

16. Wu G, Liu Y, Liu Y, et al. FGF 21 deficiency slows gastric emptying and reduces initial blood alcohol concentration in mice exposed to acute alcohol in fasting state. Biochem Biophys Res Commun 2018;497:46-50.

17. Schumann G, Liu C, O'Reilly P, et al. KLB is associated with alcohol drinking, and its gene product B-Klotho is necessary for FGF21 regulation of alcohol preference. Proc Natl Acad Sci U S A 2016;113:14372-7.

18. Zhu S, Ma L, Wu Y, et al. FGF21 treatment ameliorates alcoholic fatty liver through activation of AMPK-SIRT1 pathway. Acta Biochim Biophys Sin 2014;46:1041-8.

19. Cornu M, Oppliger W, Albert V, et al. Hepatic mTORC1 controls locomotor activity, body temperature, and lipid metabolism through FGF21. Proc Natl Acad Sci U S A 2014;111:11592-9.

20. Song P, Zechner C, Hernandez G, et al. The hormone FGF21 stimulates water drinking in response to ketogenic diet and alcohol. Cell Metab 2018;27:1338-47.e4.

21. Cheng Q, Law PK, de Gasparo M, et al. Combination of the dipeptidyl peptidase IV inhibitor LAF237 [(S)-1-[(3hydroxy-1-adamantyl) ammo] acetyl-2-cyanopyrrolidine] with the angiotensin II type 1 receptor antagonist valsartan [N-(1-oxopentyl)-N-[[2'-(1H-tetrazol-5-yl)-[1, 1'-biphenyl]-4-yl] methyl]-L-valine] enhances pancreatic islet morphology and function in a mouse model of type 2 diabetes. J Pharmacol Exp Ther 2008;327:683-91.

22. Holland WL, Adams AC, Brozinick JT, et al. An FGF21adiponectin-ceramide axis controls energy expenditure and insulin action in mice. Cell Metab 2013;17:790-7.

23. Markan KR, Naber MC, Ameka MK, et al. Circulating FGF21 is liver derived and enhances glucose uptake during 
refeeding and overfeeding. Diabetes 2014;63:4057-63.

24. Agardh EE, Lundin A, Lager A, et al. Alcohol and type 2 diabetes: The role of socioeconomic, lifestyle and psychosocial factors. Scand J Public Health 2019;47:408-16.

25. Suebsamran $\mathrm{P}$, Choenchoopon H, Rojanasaksothorn $\mathrm{S}$, et al. Association between Alcohol Consumption and Pre-Diabetes among 383,442 Thai Population Aged 15 Years and Older in Ubon Ratchathani: Analytical CrossSectional Study. J Med Assoc Thai 2016;99:S35-42.

26. Nguyen KH, Lee JH, Nyomba BG. Ethanol causes endoplasmic reticulum stress and impairment of insulin secretion in pancreatic $\beta$-cells. Alcohol 2012;46:89-99.

27. Kim JY, Song EH, Lee HJ, et al. Chronic ethanol consumption-induced pancreatic B-cell dysfunction and apoptosis through glucokinase nitration and its downregulation. J Biol Chem 2010;285:37251-62.

28. Xin Y, Kim J, Okamoto H, et al. RNA sequencing of single human islet cells reveals type 2 diabetes genes. Cell Metab 2016;24:608-15.

29. Kruse R, Vienberg SG, Vind BF, et al. Effects of insulin and exercise training on FGF21, its receptors and target genes in obesity and type 2 diabetes. Diabetologia 2017;60:2042-51.

30. Dembele K, Nguyen KH, Hernandez TA, et al. Effects of ethanol on pancreatic beta-cell death: interaction with glucose and fatty acids. Cell Biol Toxicol 2009;25:141-52.

31. Desai BN, Singhal G, Watanabe M, et al. Fibroblast growth factor 21 (FGF21) is robustly induced by ethanol and has a protective role in ethanol associated liver injury. Mol Metab 2017;6:1395-406.

32. Søberg, S, Andersen ES, Dalsgaard NB, et al. FGF21, a liver hormone that inhibits alcohol intake in mice, increases in human circulation after acute alcohol ingestion and sustained binge drinking at Oktoberfest. Mol Metab 2018;11:96-103.

33. Zhao C, Liu Y, Xiao J, et al. FGF21 mediates alcohol-induced adipose tissue lipolysis by activation of systemic release of catecholamine in mice. J Lipid Res 2015;56:1481-91.

34. Morrice N, Mcilroy GD, Tammireddy SR, et al. Elevated Fibroblast growth factor 21 (FGF21) in obese, insulin resistant states is normalised by the synthetic retinoid Fenretinide in mice. Sci Rep 2017;7:43782.

35. Tanajak P. Letter to the Editor: Parameters, Characteristics, and Criteria for Defining the Term "FGF21 Resistance". Endocrinology 2017;158:1523-24.

36. Chen X, Ward SC, Cederbaum AI, et al. Alcoholic fatty liver is enhanced in CYP2A5 knockout mice: The role of the PPAR $\alpha$-FGF21 axis. Toxicology 2017;379:12-21.

37. Maratos-Flier E. Fatty liver and FGF21 physiology. Exp
Cell Res 2017;360:2-5.

38. Karatayli E, Christidis G, Hall RA, et al. Altered Fgf21 response in alcohol induced "Acute-on-chronic liver injury” (ACLI) model. Z Gastroenterol 2019;57:P1-25.

39. So WY, Cheng Q, Xu A, et al. Loss of fibroblast growth factor 21 action induces insulin resistance, pancreatic islet hyperplasia and dysfunction in mice. Cell Death Dis 2015;6:e1707.

40. Singhal G, Chee MJ, Tan TG, et al. Fibroblast growth factor 21 (FGF21) protects against high fat diet induced inflammation and islet hyperplasia in pancreas. PLoS One 2016;11:e0148252.

41. Davis D, Garg C, Lahiri SS. Therapeutic potential of FGF21 in diabetes. J Med Plant 2017;5:364-372.

42. Simons M. Fibroblast Growth Factors: Biology And Clinical Application-Fgf Biology And Therapeutics. World Scientific; 2016.

43. Chai J, Tarnawski AS. Serum response factor: discovery, biochemistry, biological roles and implications for tissue injury healing. J Physiol Pharmacol 2002;53:147-57.

44. Szybowska P, Kostas M, Wesche J, et al. Cancer Mutations in FGFR2 Prevent a Negative Feedback Loop Mediated by the ERK1/2 Pathway. Cells 2019;8. doi: 10.3390/ cells8060518.

45. Gupta S, Wang F, Holly EA, et al. Risk of pancreatic cancer by alcohol dose, duration, and pattern of consumption, including binge drinking: a populationbased study. Cancer Causes Control 2010;21:1047-59.

46. Kesseli SJ, Smith KA, Gardner TB. Total pancreatectomy with islet autologous transplantation: the cure for chronic pancreatitis? Clin Transl Gastroenterol 2015;6:e73.

47. Kim JY, Lee DY, Lee YJ, et al. Chronic alcohol consumption potentiates the development of diabetes through pancreatic B-cell dysfunction. World J Biol Chem 2015;6:1.

48. He L, Marecki, JC, Serrero G, et al. Dose-dependent effects of alcohol on insulin signaling: partial explanation for biphasic alcohol impact on human health. Molecular Endocrinology 2007;21:2541-50.

49. So WY, Cheng Q, Chen L, et al. High glucose represses B-klotho expression and impairs fibroblast growth factor 21 action in mouse pancreatic islets: involvement of peroxisome proliferator-activated receptor $\gamma$ signaling. Diabetes 2013;62:3751-9.

Cite this article as: Yang BC, Wu SY, Leung PS. Alcohol ingestion induces pancreatic islet dysfunction and apoptosis via mediation of FGF21 resistance. Ann Transl Med 2020;8(6):310. doi: $10.21037 /$ atm.2020.02.129 
1 week
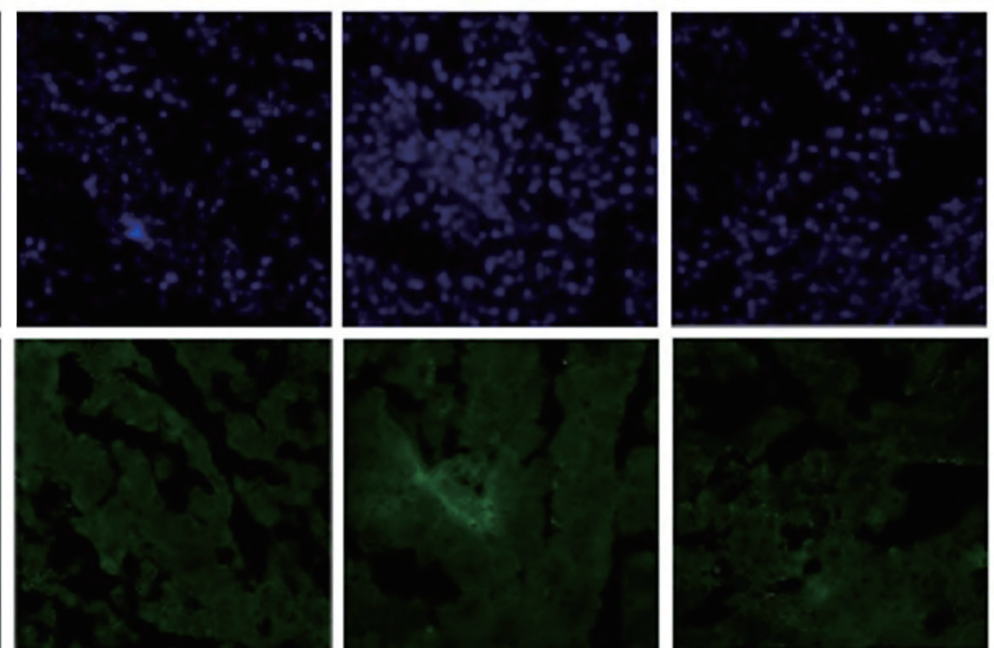

INSULIN

GF21

Merge
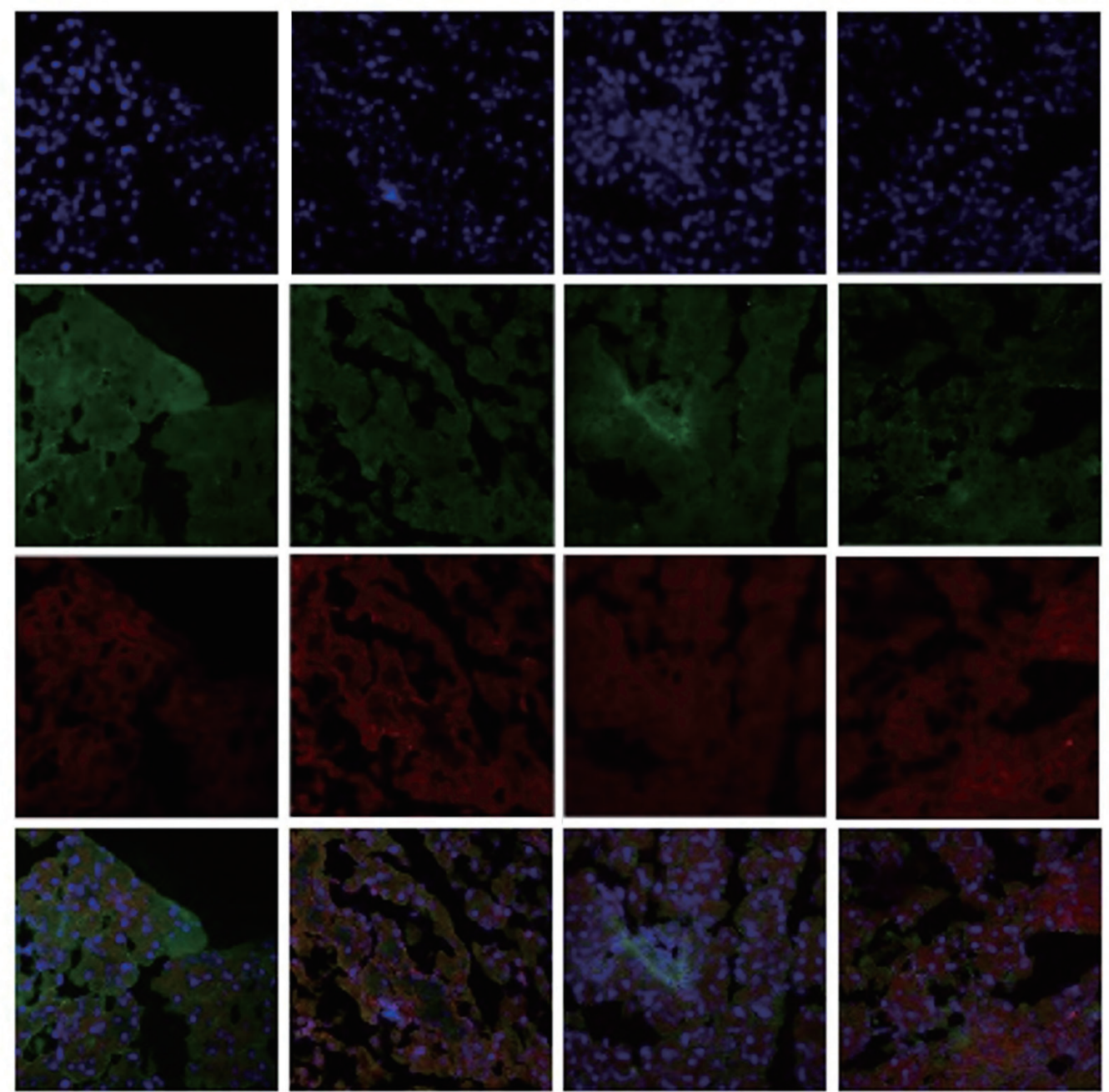

Ethanol
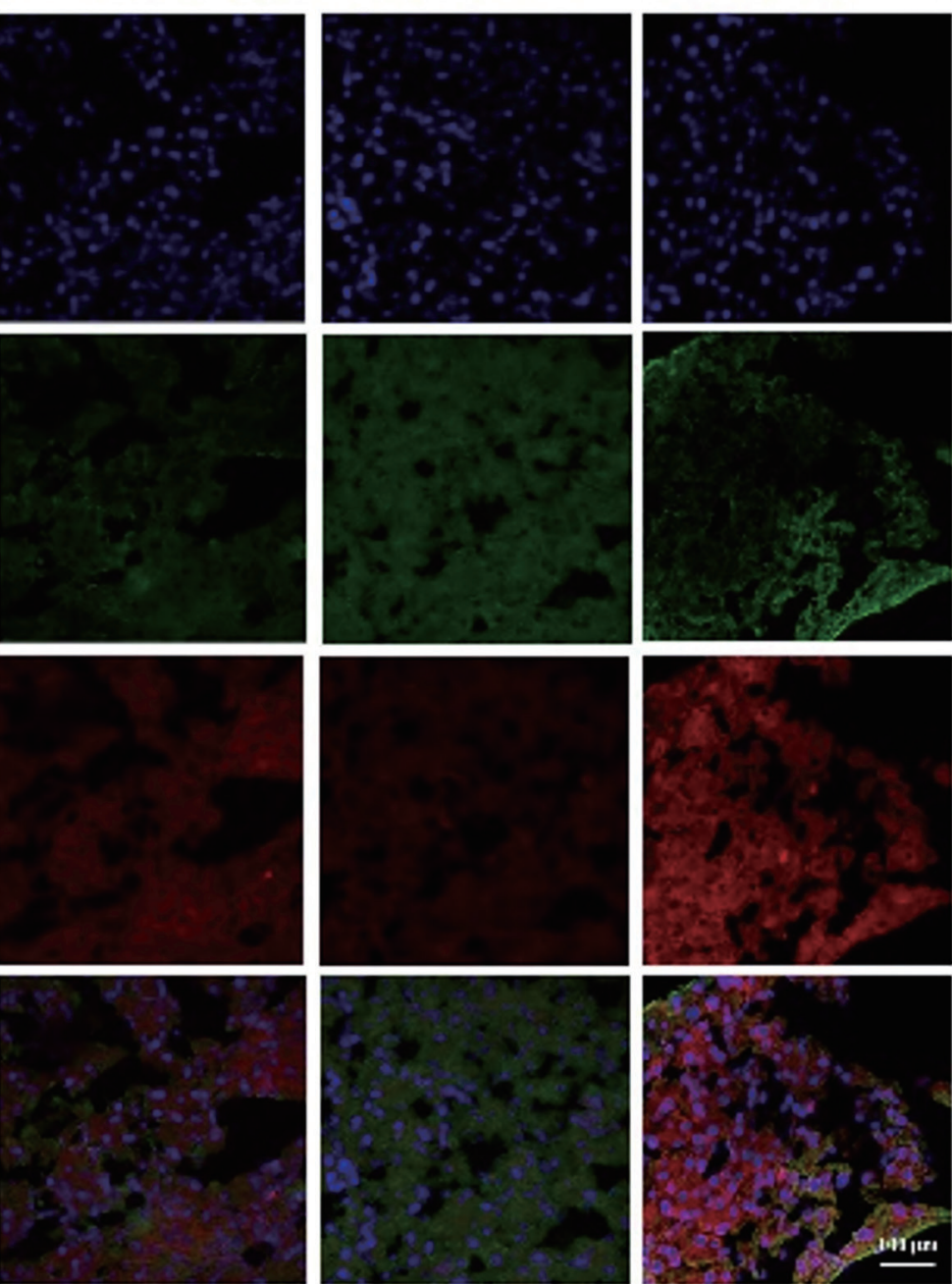

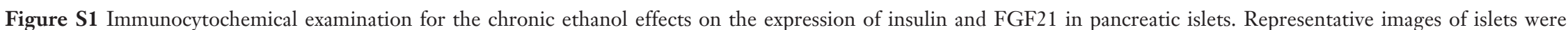
labeled for DAPI (blue), insulin (green) and FGF21 (red) Scale bar =100 $\mu \mathrm{m}$. 